\title{
Studies of Twins: Can they Shed Light on the Fetal Origins of Adult Disease Hypothesis?
}

\author{
Ruth Morley', Terry Dwyer 2, and John B. Carlin' \\ 'Clinical Epidemiology and Biostatistics Unit, University of Melbourne Department of Paediatrics, and Murdoch Children's Research Institute, \\ Royal Children's Hospital, Melbourne, Australia. \\ ${ }^{2}$ Menzies Centre for Population Health Research, Hobart, Tasmania, Australia
}

\begin{abstract}
There has been much interest in evidence that people with lower birthweight have higher risk of adult cardiovascular disease, but the causal pathways underlying such observations are uncertain. Study of twins offers an opportunity to shed light on these pathways, in three different ways. First, in a twin pregnancy maternal nutritional resources and the "supply line" to the fetuses will be more "stretched". We hypothesise that study of twin pregnancies is a more efficient way to identify modifiable maternal factors that influence later health than studies of singleton pregnancies. Second, twins have lower birthweight than singletons. Comparison of cardiovascular disease risk in twins versus that in singletons will provide insight into whether birthweight per se is in the underlying causal pathway of interest, and whether factors constraining fetal growth of twins (versus singletons) affect later outcome. Third, twin cohorts provide an opportunity to investigate the role of "shared" factors versus factors affecting each individual fetus, by comparing results of within-cohort versus within-pair analyses. Generalisability of findings in twins is debated. We suggest that findings in monochorionic twins (or in the absence of chorionicity data, those from monozygotic twins) need to be interpreted with caution.
\end{abstract}

\section{The Fetal Origins of Adult Disease Hypothesis}

There is evidence from human populations worldwide that there is a negative association between birthweight and blood pressure, risk of Type 2 diabetes and coronary heart disease (CHD) in later life (Byrne \& Phillips et al., 2000; Waterland \& Garza, 1999). This epidemiological evidence is the basis for the hypothesis that exposures during fetal life can affect later health — "the fetal origins of adult disease".

Some have questioned the magnitude of such associations (Huxley et al., 2002) and others whether the relationships are causal or there are alternative explanations such as differences in postnatal growth, socioeconomic confounding, or genetic factors (Henriksen \& Clausen, 2002; Kramer et al., 2000; Lucas et al., 1999). In animals, gestational factors can be studied experimentally in inbred and relatively genetically homogeneous laboratory animals, with the postnatal environment strictly controlled. In human populations this strict experimental approach is, of course, not possible and there is greater genetic heterogeneity than in laboratory animals, so questions remain about socioeconomic confounding (associated with birthweight, postnatal environment and risk of disease) and the role of genetic factors (Morley \& Dwyer, 2001).

We recently suggested that there are different kinds of factors operating during gestation (Morley et al., 2002). Some factors (Type A in Figure 1) would influence fetal growth without affecting risk of later disease, whereas we have provided evidence that there are likely to be other factors (Type D) that influence later disease risk but not fetal growth. Yet others (Type C) could influence both fetal growth and disease risk, or disease risk because of reduced fetal growth (Type B). We also indicated that from a public health point of view there is a need to shift the research focus from fetal growth or size at birth to modifiable factors during gestation.

\section{Investigating the Fetal Origins of Adult Disease in Cohorts of Twins}

Data from twins can be used in three different ways to investigate the fetal origins of adult disease.

\section{Investigation of The Role of Modifiable Maternal Factors}

We hypothesize that the effect of modifiable maternal factors, such as maternal nutrition, on offspring outcome will be more readily apparent in twin pregnancies than in singleton pregnancies, since maternal resources and the supply line to the fetuses will be more "stretched". Thus studies of twins may be a more efficient way to identify maternal factors that influence total (or mean) birthweight of a pair or factors that directly affect offspring health, compared with studies of singleton pregnancies. However, we have no evidence that this is the case, and it possible that the general "constraint" on fetal growth in twins compensates to some extent for the increased demands on maternal resources.

Address for correspondence: Dr Ruth Morley, University of Melbourne Department of Paediatrics, Royal Children's Hospital, Flemington Road, Parkville, Victoria 3052, Australia. Email: morleyr@unimelb.edu.au 


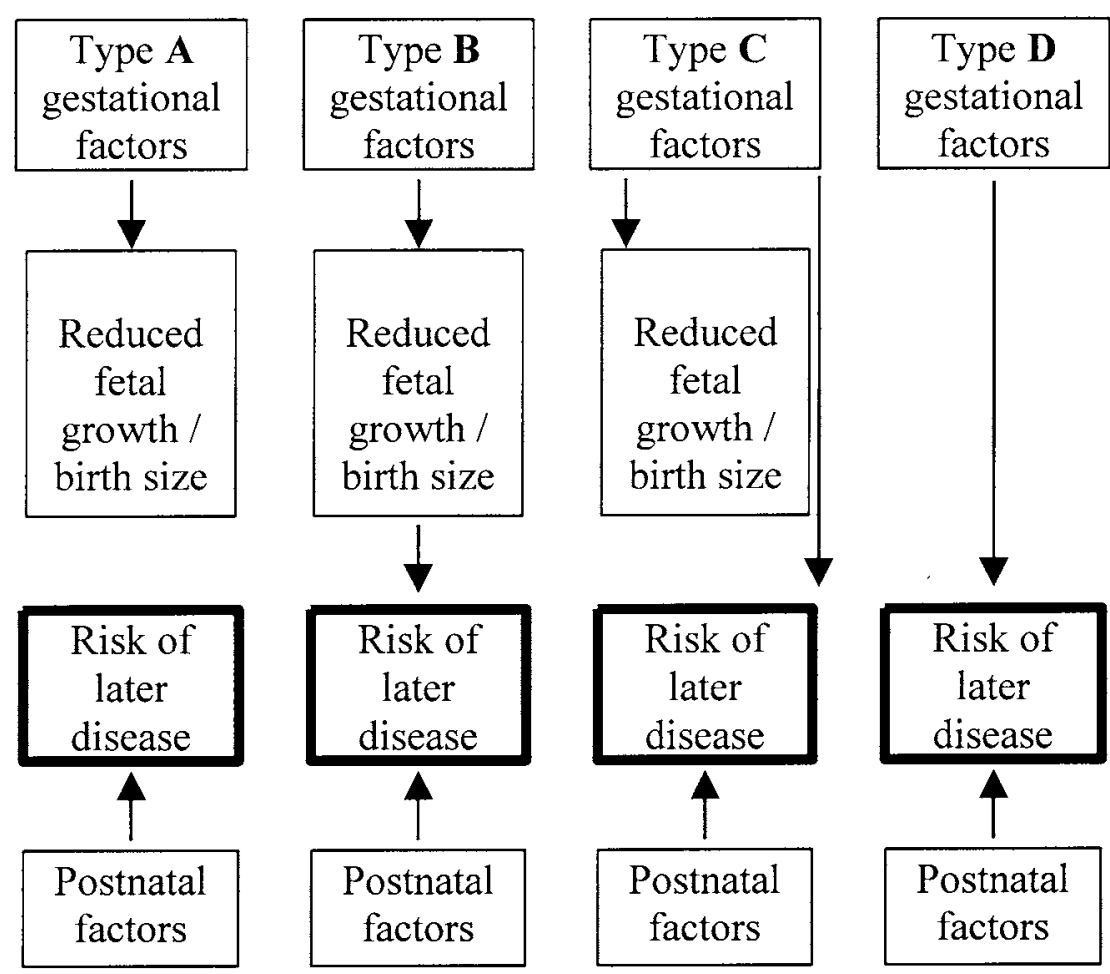

\section{Figure 1}

Types of factor operating during gestation.

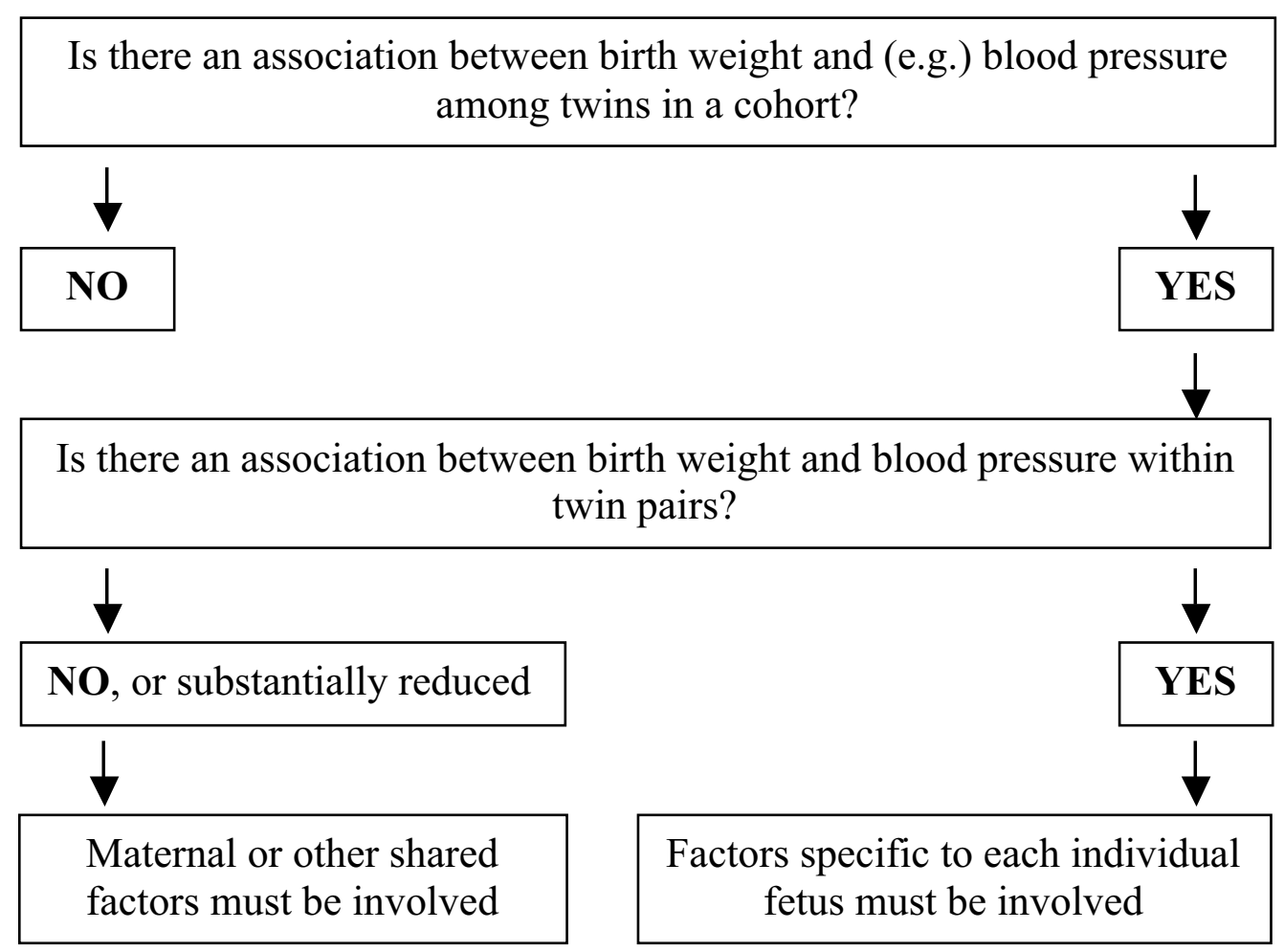

Figure 2

Within-cohort versus within-pair analyses. 


\section{Comparison of Twins with Singletons}

As a group, twins have lower birthweight than singletons. This relates partly to decreased median gestation length in twins, and partly to reduced size for gestation (Taylor et al., 1998). Some investigators have compared mortality after age 6 years, cardiovascular mortality or risk of CHD in twins (as a group) with that in singletons, on the grounds that if people with lower birthweight have an increased risk of later disease, then twins should be at higher risk than singletons. No differences were found (Christensen et al., 1995; Christensen et al., 2001; Vagero et al., 1994).

We can infer that birthweight per se is not a determinant of later health, and that factors causing twins, as a group, to have lower birthweight than singletons, must be of Type A with respect to mortality and CHD. Nevertheless, factors of Types B and/or C must also be operating because in most cohorts of twins (Dwyer et al., 1999; IJzerman et al., 2000; Johansson-Kark et al., 2002; Loos et al., 2001; Nowson et al., 2001; Zhang et al., 2001; but not Baird et al., 2001) as in cohorts of singletons, an inverse association has been seen between birthweight and blood pressure. However, we do not know whether increased mean blood pressure is an important intermediate in the causal pathway(s) underlying the association between lower birthweight and increased risk of CHD (Koupilova et al., 1999).

Twins have a shorter median gestation than singletons so we can also infer, from the findings regarding CHD or mortality in twins versus singletons, that these outcomes are not related to gestational age. Another important inference from the studies already mentioned, comparing later health of twins and singletons, is that the accelerated postnatal growth seen in twins generally is not involved in any causal pathway leading to increased risk of CHD or mortality.

In a study of 132 same-sex adult twin pairs discordant for acute myocardial infarction (AMI), there was no association between birthweight and AMI (Hubinette et al., 2001). However, this was not a representative population of twins.

\section{Within-Cohort Versus Within-pair Analayses}

Conventionally, twin data have been used to separate genetic from environmental causes by comparing concordance for disease in $\mathrm{DZ}$ versus $\mathrm{MZ}$ pairs. Recently, twin studies have also been used to shed light on the fetal origins hypothesis.

Twins share many factors during gestation because they have the same mother, and almost invariably, the same father. Birthweight discordance (difference in birthweight within a twin pair) cannot be determined by these shared factors and must relate to factors affecting growth of each individual fetus. If an association between birthweight and outcomes of interest (e.g., blood pressure) is seen within a cohort of twins, within-pair analyses can shed light on the type of factors involved (Dwyer et al., 2002). If the association remains in within-pair analyses, this suggests that factors specific to each individual (like the individual fetal supply of nutrients and oxygen or even postnatal differences like differences in growth) must be involved in the underlying causal pathways (Figure 2). Conversely, if the relationship disappears or substantially diminishes in within-pair analyses, then factors common to the pair (like maternal nutrition or socioeconomic status) must be involved. It is of course possible that both common and individual factors are involved, in which case we should see a reduction rather than disappearance of the association in within-pair analyses.

Twins can be further divided into $\mathrm{DZ}$ and $\mathrm{MZ}$ pairs. If the reduction in strength of the association is more evident in within-pair analyses in MZ twins than in DZ twins, we can consider the possibility that genetic factors were involved in the underlying causal pathways. However, we need to bear in mind that $\mathrm{MZ}$ and not $\mathrm{DZ}$ pairs can share one placenta.

\section{$\overline{\text { Potential Problems with Interpretation }}$ of Data from Twins}

An important issue is whether data from twins can be used to shed light on causal pathways operating in cohorts of singletons. We discuss here issues specific to twin pregnancies, and whether they influence birth size or cardiovascular risk factors.

\section{Zygosity, Chorionicity and Umbilical Cord Insertion}

Twins can be dizygotic (DZ), derived from two separate fertilised oocytes, or monozygotic (MZ), derived from one fertilised oocyte that splits at the blastocyst stage. $M Z$ twins are not necessarily genetically identical, and can differ in terms of number and morphology of chromosomes, DNA mutations and epigenetic modifications (Gringras \& Chenet, 2001). The extent of such discordance is not known.

There are four different types of twin chorionicity (placentation), as shown in Figure 2. DZ twins always have a placenta each (are dichorionic). Sometimes the two placentas fuse but the fetal circulations remain separate. $M Z$ twins can have placentas of any of the four types in Figure 3, depending on the timing of embryonic splitting.

Monochorionicity (affecting approximately two thirds of $\mathrm{MZ}$ twins) is an important issue for two reasons. First, anastomoses between the two fetal circulations are common and can sometimes lead to twin-twin transfusion syndrome, which can affect both birthweight discordance and later vascular structure and function (Cheung et al., 2000). Second, if circulating factors in a compromised fetus are involved in "programming" that individual for later disease, then in monochorionic pregnancies factors in the circulation of a compromised twin could potentially affect the uncompromised co-twin via inter-twin vascular connections.

MZ twins have lower median birthweight than DZ twins, and there is greater birthweight discordance in monochorionic versus dichorionic twin pairs (Victoria et al., 2001). Zygosity and chorionicity may also influence some outcomes of interest. Few twin studies have information about chorionicity and there is no published evidence regarding chorionicity and cardiovascular outcomes. There is evidence that $M Z$ twins have a more adverse lipid profile than DZ twins, and also evidence suggesting that $\mathrm{MZ}$ twins have higher fasting plasma glucose and insulin concentrations (Poulsen et al., 2002; Poulsen et al., 1999), though these findings await confirmation in other cohorts. Another large study found that mortality among female 
a) Separate dichorionic placentas (18\% of MZ, $58 \%$ of DZ)

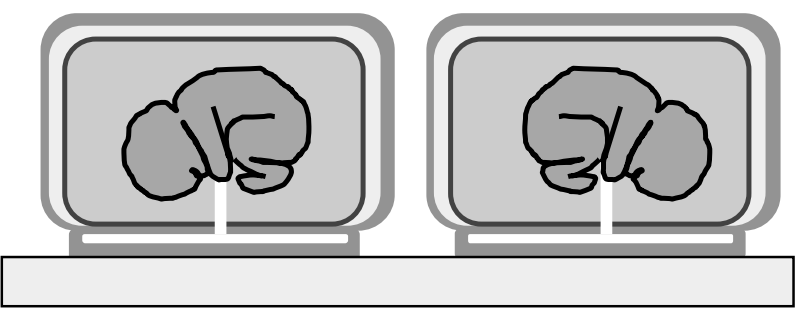

b) Fused dichorionic (DC) placentas. (14\% of MZ, $42 \%$ of DZ)

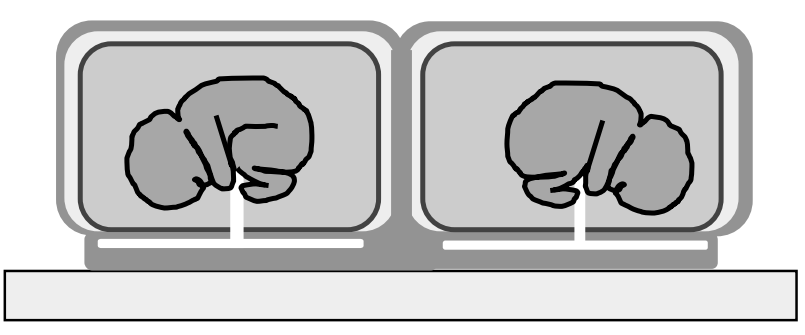

c) Monochorionic diamniotic placenta (64\% of MZ)

d) Monochorionic monoamniotic placenta (4\% of MZ)

Inter-fetal vascular anastomoses in the

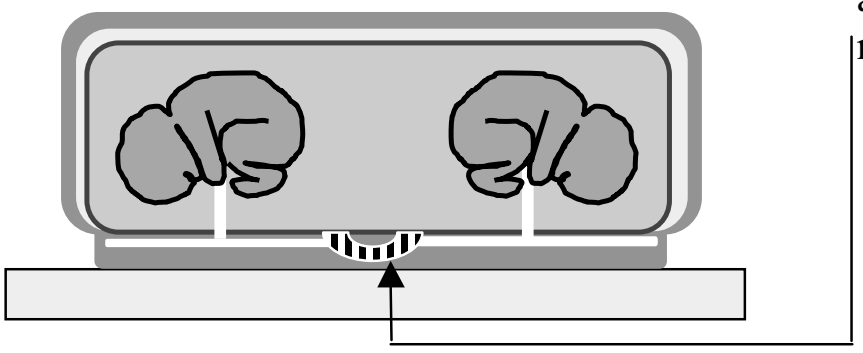
majority

Footnote. $\mathrm{MZ}=$ monozygotic. $\mathrm{DZ}=$ dizygotic . 
dizygotic twins was 1.77 times higher than among monozygotic twins at age 30-59 (Christensen et al., 1995)

Umbilical cord insertion can also vary, though again few studies have information about this. Generally the cord inserts at or near the centre of the placental disc, but it can insert at the periphery of the disc and in extreme cases can be velamentous (run in the amniotic membrane for some distance from the placenta). There is debate as to whether umbilical cord insertion influences birthweight in all twins (Loos et al., 2001) or only in monochorionic twins (Hanley et al., 2002), among whom location of each cord insertion determines the proportion of placental parenchyma allocated to each twin (Machin, 2001). No association has been seen between cord insertion and birthweight in singleton infants (Woods \& Malan, 1978; Liu et al., 2002).

\section{Gender Mix}

In multifetal animals (such as mice), testosterone level of both males and females is higher if they are located, in utero, between two males versus two females (vom Saal, 1989). In humans, no study has measured fetal or neonatal testosterone levels in relation to whether the co-twin is male or female.

There is conflicting evidence on how gender-mix in a twin pair influences birthweight. In two large studies, (one of DZ twins only), female infants had slightly higher birthweight if they had a male co-twin versus a female co-twin, but data on gestation were not available (Blumrosen et al., 2002; Glinianaia et al., 1998). In another large study, length of gestation of twin pregnancies was significantly longer when one or both fetuses were female (Loos et al., 2001), so that male infants from boy-girl pairs (all DZ) weighed $78 \mathrm{~g}$ more at birth than those from boy-boy (MZ and DZ) pairs. Girls' birthweights were the same whether they were from same- or different-sex pairs. However, whatever the nature of the association between gender mix and birthweight, effects are small in relation to the fetal origins hypothesis. There is no evidence to date regarding gender mix and cardiovascular risk factors.

\section{Conclusions}

We suggest there is no reason why findings in dichorionic twins, regarding the causal pathways underlying the association seen between birthweight and outcome, should not be qualitatively valid for singletons, provided analyses take appropriate account of specific issues such as zygosity, gestation length and gender mix.

Greater caution needs to be exercised regarding data from monochorionic twins. New studies of twins need to be prospective so that essential data that would not be available retrospectively (including information on chorionicity and maternal exposures during gestation) can be collected.

\section{$\overline{\text { Acknowledgments }}$}

The authors thank Professor Roger Short for helpful suggestions. Ruth Morley is supported by VicHealth (the Victorian Health Promotion Foundation).

\section{References}

Baird, J., Osmond, C., MacGreggor, A., Sneider, C. N., \& Phillips D. I. W. (2001). Testing the fetal origins hypothesis in twins: The Birmingham study. Diabetalogia, 44, 33-39

Blumrosen, E., Goldman, R. D., \& Blickstein, I. (2002). Growth discordance and the effect of a male twin on birthweight of its female co-twin: A population-based study. Journal of Perinatal Medicine, 30, 510-513.

Byrne, C. D., \& Phillips, D. I. (2001). Fetal origins of adult disease: Epidemiology and mechanisms. Journal of Clinical Pathology, 53, 822-828.

Cheung, Y. F., Taylor, M. J., Fisk, N. M., Redington, A. N., \& Gardiner, H. M. (2000). Fetal origins of reduced arterial distensibility in the donor twin in twin-twin transfusion syndrome. Lancet, 355, 1157-1158.

Christensen, K., Stovring, H., \& McGue, M. (2001). Do genetic factors contribute to the association between birthweight and blood pressure? Journal of Epidemiology and Community Health, 55, 583-587.

Christensen, K., Vaupel, J. W., Holm, N. V., \& Yashin, A. I. (1995). Mortality among twins after age 6: Fetal origins hypothesis versus twin method. British Medical Journal, 310, 432-436.

Christensen, K., Wienke, A., Skytthe, A., Holm, N. V., Vaupel, J. W., \& Yashin, A. I. (2001). Cardiovascular mortality in twins and the fetal origins hypothesis. Twin Research, 4, 344-349.

Dwyer, T., Blizzard, L., Morley, R., \& Ponsonby, A. L. (1999). Within pair association between birthweight and blood pressure at age 8 in twins from a cohort study. British Medical Journal, 319, 1325-1329.

Dwyer, T., Morley, R., \& Blizzard, L. (2002). Twins and fetal origins hypothesis: Within-pair analyses. Lancet, 359, 2205-2206.

Glinianaia, S. V., Magnus, P., Harris, J. R., \& Tambs, K. (1998). Is there a consequence for fetal growth of having an unlikesexed cohabitant in utero? International Journal of Epidemiology, 27, 657-659.

Gringras, P., \& Chen, W. (2001). Mechanisms for differences in monozygous twins. Early Human Development, 64, 105-117.

Hanley, M. L., Ananth, C. V., Shen-Schwarz, S., Smulian, J. C., Lai, Y. L., \& Vintzileos, A. M. (2002). Placental cord insertion and birthweight discordancy in twin gestations. Obstetrics and Gynecology, 99, 477-482.

Henriksen, T., \& Clausen, T. (2002). The fetal origins hypothesis: Placental insufficiency and inheritance versus maternal malnutrition in well-nourished populations. Acta Obstetricia et Gynecologica Scandinavica, 81, 112-114.

Hubinette, A., Cnattingius, S., Ekbom, A., de Faire, U., Kramer, M., \& Lichtenstein, P. (2001). Birthweight, early environment, and genetics: A study of twins discordant for acute myocardial infarction. Lancet, 357, 1997-2001.

Huxley, R., Neil, A., \& Collins, R. (2002). Unravelling the fetal origins hypothesis: Is there really an inverse association between birthweight and subsequent blood pressure? Lancet, 360, 659-665.

Ijzerman, R. G., Stehouwer, C. D., \& Boomsma, D. I. (2000). Evidence for genetic factors explaining the birthweight-blood pressure relation. Analysis in twins. Hypertension, 36, 1008-1012. 
Johansson-Kark, M., Rasmussen, F., De Stavola, B., \& Leon, D. A. (2002). Fetal growth and systolic blood pressure in young adulthood: The Swedish Young Male Twins Study. Paediatric and Perinatal Epidemiology, 16, 200-209.

Koupilova, I., Leon, D. A., McKeigue, P. M., \& Lithell, H. O. (1999). Is the effect of low birthweight on cardiovascular mortality mediated through high blood pressure? Journal of Hypertension, 17, 19-25.

Kramer, M. S. (2000). Association between restricted fetal growth and adult chronic disease: Is it causal? Is it important? American Journal of Epidemiology, 152, 605-608.

Liu, C. C., Pretorius, D. H., Scioscia, A. L., \& Hull, A. D. (2002). Sonographic prenatal diagnosis of marginal placental cord insertion: Clinical importance. Journal of Ultrasound Medicine, 21, 627-632.

Loos, R. J., Derom, C., Derom, R., \& Vlietinck, R. (2001). Birthweight in liveborn twins: The influence of the umbilical cord insertion and fusion of placentas. British Journal of Obstetrics and Gynaecology, 108, 943-948.

Loos, R. J., Derom, C., Eeckels, R., Derom, R., \& Vlietinck, R. (2001). Length of gestation and birthweight in dizygotic twins. Lancet, 358, 560-561.

Loos, R. J., Fagard, R., Beunen, G., Derom, C., \& Vlietinck, R. (2001). Birthweight and blood pressure in young adults: A prospective twin study. Circulation, 104, 1633-1638.

Lucas, A., Fewtrell, M. S., \& Cole, T. J. (1999). Fetal origins of adult disease - The hypothesis revisited. British Medical Journal, 319, 245-249.

Machin, G. (2001). Placentation in multiple births. Twin Research, 4, 150-155.

Morley, R., \& Dwyer, T. (2001). Fetal origins of adult disease? Clinical and Experimental Pharmacology and Physiology, 28, 962-966.

Morley, R., Owens, J., Blair, E., \& Dwyer, T. (2002). Is birthweight a good marker for gestational exposures that increase the risk of adult disease. Paediatric and Perinatal Epidemiology, 16, 194-199.

Nowson, C. A., MacInnis, R. J., Hopper, J. L., Alexander, J. L., Paton, L. M., Margerison, C., \& Wark, J. D. (2001). Association of birthweight and current body size to blood pressure in female twins. Twin Research, 4, 378-384.

Poulsen, P., Vaag, A., \& Beck-Nielsen, H. (1999). Does zygosity influence the metabolic profile of twins? A population based cross sectional study. British Medical Journal, 319, 151-154.

Poulsen, P., Vaag, A., \& Beck-Nielsen, H. (2002). The influence of zygosity status on blood pressure and on lipid profiles in male and female twins. Journal of Hypertension, 20, 645-649.

Taylor, G. M., Owen, P., \& Mires, G. J. (1998). Foetal growth velocities in twin pregnancies. Twin Research, 1, 9-14.

Vagero, D., \& Leon, D. (1994). Ischaemic heart disease and low birthweight: A test of the fetal-origins hypothesis from the Swedish Twin Registry. Lancet, 343, 260-263.

Victoria, A., Mora, G., \& Arias, F. (2001). Perinatal outcome, placental pathology, and severity of discordance in monochorionic and dichorionic twins. Obstetrics and Gynecology, 97, 310-315.

vom Saal, F. S. (1989). Sexual differentiation in litter-bearing mammals: Influence of sex of adjacent fetuses in utero. Journal of Animal Science, 67, 1824-1840.

Waterland, R. A., \& Garza, C. (1999). Potential mechanisms of metabolic imprinting that lead to chronic disease. American Journal of Clinical Nutrition, 69, 179-197.

Woods, D. L., \& Malan, A. F. (1978). The site of umbilical cord insertion and birthweight. British Journal of Obstetrics and Gynaecology, 85, 332-333.

Zhang, J., Brenner, R. A., \& Klebanoff, M. A. (2001). Differences in birthweight and blood pressure at age 7 years among twins. American Journal of Epidemiology, 153, 779-782. 